\title{
Chronic pulmonary histoplasmosis in an Irishman
}

\author{
M MADDEN, JD KENNEDY, HT HITCHCOCK, D O'BEIRN
}

From the Departments of Pathology and Medicine, Regional Hospital and University College, Galway, Ireland

We present the case history of a 48-year-old Irish engineer who developed active pulmonary histoplasmosis. He presented with mild symptoms and a markedly abnormal chest radiograph five years after his return from areas where histoplasmosis is endemic. The determinants of the factors initiating activation of disease and the explanation for the period of dormancy of infection remain speculative.

\section{Case report}

The patient, a 48-year-old Irish engineer, was admitted to hospital on 6 December 1978. He complained of dry cough and intermittent sweating for six weeks. There were no other symptoms. He stopped smoking cigarettes six years before admission and was a pipe smoker until this illness. A considerable portion of his life had been spent in the tropics. In 1945-50 he was in Malaya for 12 months; in 1957-58 he was in Nigeria for 12 months; in 1958-59 he was in Senegal for nine months; in 1959-60 he was in Malta for nine months; in 1969-70 he was in Zambia. In 1973 he returned to Ireland and has lived here since.

On examination he was a fit looking man. There was no lymphadenopathy. Blood pressure was 130/90. A soft systolic murmur at the lower left sternal edge was noted. The lungs were clinically clear. He had normal breath sounds over both lungs and no added sounds. The abdomen, genitalia and nervous system were normal on examination.

Chest radiography showed multiple discrete opacities in both mid and lower zones (fig 1). The erythrocyte sedimentation rate was $63 \mathrm{~mm}$ in one hour. The Mantoux test was positive. Pulmonary function tests showed a mild restrictive defect. Peripheral lung biopsy showed interstitial fibrosis. Other investigations including full blood count, urea and electrolytes, electrocardiograph, intravenous pyelogram, liver biopsy, and bronchoscopic appearances were normal. A left basal segmentectomy was carried out on 18 December 1978.

\section{PATHOLOGICAL FINDINGS}

The segment of lung weighed $220 \mathrm{~g}$ and contained several circumscribed masses of firm white tissue, similar on gross examination to metastatic tumour tissue. The largest mass situated in the left anterior basal segment measured $5 \mathrm{~cm}$ in maximal dimensions. Absence of

Address for reprint requests: Dr M Madden, Department of Pathology, Regional Hospital Galway, Galway, Ireland.

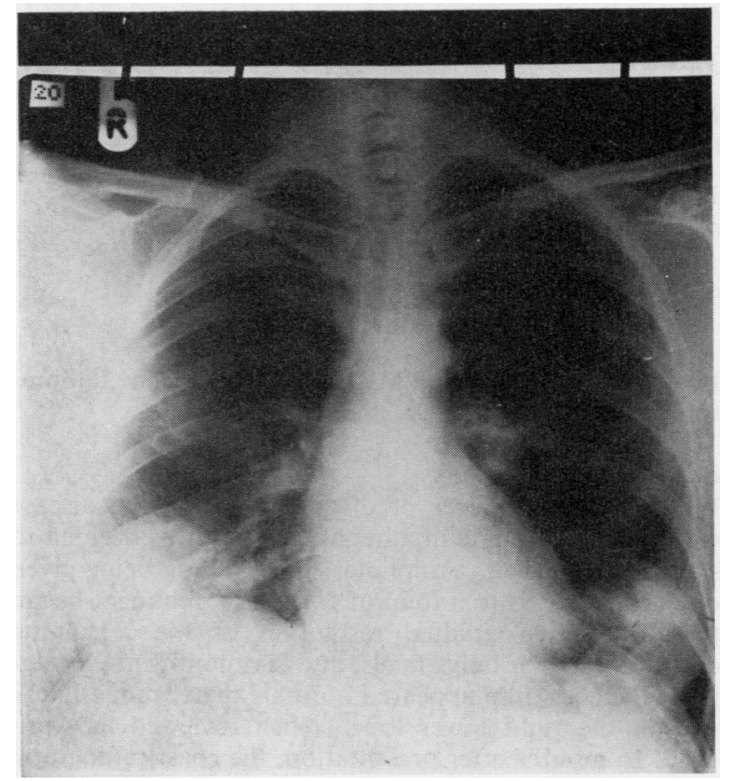

Fig 1 Postero-anterior chest radiograph showing multiple discrete opacities in both mid lower zones.

calcification was confirmed by radiographic examination. There was no pleural reaction and no cavity formation.

Histological examination showed all the lesions to have similar features, being composed mainly of proliferating fibroblasts and histiocytes in a fibrous tissue stroma.

There were a large number of histiocytic granulomas with giant cells containing doubly refractile ovoid bodies. There was no caseation in the granulomas but there were scattered islands of necrosis 1-2 mm in diameter. At the periphery of the lesions there was a thin and incomplete rim of fibrous tissue, and diffuse infiltration of the alveoli by macrophages. Doubly refractile ovoid bodies $2-4 \mu \mathrm{m}$ in diameter were present in macrophages and giant cells (fig 2). In addition, large numbers of these bodies were present outside cells in necrotic areas. These had the staining properties of Histoplasma capsulatum, being easily stained by Gomori's methenamine silver and being PAS positive.

Their histological identity was confirmed by Dr WStC Symmers (London) and subsequently Histoplasma capsulatum was cultured from lung tissue by Professor 


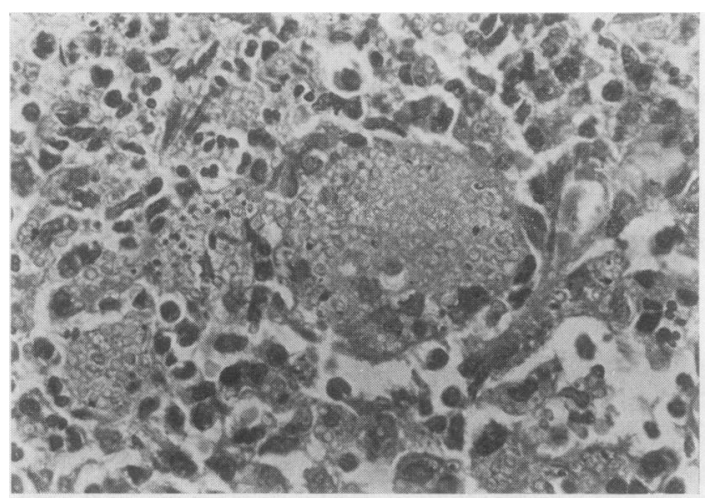

Fig 2 Intracellular parasitisation of giant cells and histiocytes by myriads of Histoplasma capsulatum. Extracellular organisms are also present. (PAS, original magnification $\times 400$ ).

DWR MacKenzie at the Mycological Reference Laboratory in London.

\section{CLINICAL PROGRESS}

In view of the danger of dissemination of the disease which may terminate in adrenal failure it was decided to start treatment with Amphotericin B, $50 \mathrm{mg}$ being given on alternate days to a total of $1 \mathrm{~g}$. Since treatment began there has been gradual resolution of the remaining opacities in both lungs fields, and six months after diagnosis the chest film appeared normal, apart from a linear scar in the right lower lobe. When reviewed in April 1980,16 months after presentation, the chest radiograph remained clear.

\section{Discussion}

Two strains of histoplasma are now recognised, the classical Histoplasma capsulatum and a larger species, Histoplasma dubosii. Infection with Histoplasma dubosii has been reported only from central Africa and pulmonary lesions are uncommon. Histoplasmosis is endemic where the environment can support the saprophytic phase of Histoplasma capulatum. It is interesting that this patient had been in so many parts of the world where histoplasmosis occurs-Malaysia, Nigeria, Senegal, and Zambia.

The pathological findings in this patient fall into the category of the pneumonic phase of active chronic pulmonary histoplasmosis. The outcome of such lesions is impossible to predict from available data. Goodwin et $a^{1}$ reported healing in such pneumonic foci without specific antifungal therapy. However, they emphasised that there were few organisms visible in the cases studied. In view of the very heavy parasitisation obvious on histological sections in our case it was felt that disseminated histoplasmosis could ensue and antifungal therapy was indicated. It is also noted that Sutliff et $a l^{2}$ reported pneumonic infiltrates in association with cavitatory disease.

The inactive lesion known as the histoplasmoma may simulate active pneumonic foci on chest radiographs and enlargement of histoplasmomas has also been demonstrated radiologically. ${ }^{3}$ However, the histoplasmoma has a characteristic histological appearance consisting of concentric layers of necrotic and fibrous tissue. Cultures from histoplasmomas are negative, indicating that the organisms are dead.

MacLeod $e t$ al, in reviewing the cases of active histoplasmosis occurring in the British Isles, have stressed that disseminated disease is the outstanding presentation of histoplasmosis. ${ }^{4}$ Most recognised cases of active histoplasmosis occurring in the British Isles have been infected in India, the Far East, or Africa with little importation of active disease from the American continents. Symmers, in a study of North Europeans who had contracted infection in South East Asia, noted a peculiar cyst form of the histoplasma organism present in the tissues which may represent an Asian variant strain. ${ }^{5}$

The diagnosis of histoplasmosis should be considered in those with a history of travel abroad bearing in mind that the incubation may be more than 30 years.

We would like to express our thanks to Dr WStC Symmers and Professor DWR MacKenzie for their help in preparing this paper.

\section{References}

${ }^{1}$ Goodwin RAJr, Desprez RM. Histoplasmosis. Am Rev Respir Dis 1978;117:929-56.

${ }^{2}$ Sutliff WD, Hughes F, Urlich E, Burkett CL. Active chronic pulmonary histoplasmosis. Arch Intern Med 1953; 92:571-85.

${ }^{3}$ Goodwin RAJr, Snell JDJr. The enlarging histoplasmoma. Am Rev Respir Dis 1969;100:1-12.

${ }^{4}$ MacLeod WM, Murray IG, Davidson J, Gibbs DD. Histoplasmosis. A review and account of three patients diagnosed in Great Britain. Thorax 1972;27:6-17.

${ }^{5}$ Symmers WStC. Histoplasmosis in Southern and SouthEastern Asia. Ann Soc Belg Med Trop 1972;52:435-58. 